Available online on 15.03 .2020 at http://jddtonline.info
Open Access to Pharmaceutical and Medical Research
unrestricted non-commercial use, provided the original work is properly cited

Open@ Access

Research Article

\title{
Antioxidant activity, Total Phenolic and Flavonoid Contents and Cytotoxic activity of Euphorbia aegyptiaca
}

\author{
Osman Adam Osman Adam ${ }^{*}$, Ragaa Satti Mohmmed Abadi ${ }^{2}$ and Saad Mohamed Hussein Ayoub ${ }^{1}$ \\ 1 Department of Pharmacognosy, Faculty of Pharmacy, Al-Neelain University. Khartoum, Sudan \\ 2 Department of Chemistry, Faculty of Science and Technology, Al-Neelain University. Khartoum, Sudan
}

\begin{abstract}
Euphorbia aegyptiaca is a herbaceous plant traditionally used in Sudan for treatment of various diseases, and the study of this plant is still limited. The aim of the present study was to screen the phytochemicals and to assess the Antioxidant activity, total phenolic, flavonoid contents and cytotoxic activity of Euphorbia aegyptiaca. The plant material was extracted successively by Soxhlet apparatus using n-hexane, chloroform and methanol. The chemical constituents of the extracts were carried out using the standard procedures. The Folin- Ciocalteu and Aluminium chloride method was employed to calculate the total phenolic and flavonoid content, respectively. The antioxidant activity, was assessed by measuring the scavenging activity of the DPPH (2.2Di (4-tert-octylphenyl)-1-picryl-hydrazyl) and Propyl Gallate as standard antioxidants. While cytotoxic activities were screened using brine shrimp. Phytochemical screening studies revealed that flavonoids, tannins, coumarins, saponins, sterols, terpenes, anthraquinones and alkaloids were the main phytochemicals present in extracts of E. aegyptiaca. The methanol extract showed the highest level of total phenolic contents $(173.49 \pm 2.427 \mathrm{mg} \mathrm{GAE} / \mathrm{g}$ ) and flavonoid content (239.53 $\pm 7.90 \mathrm{mg}$ QE/g), and the highest antioxidant activity $89 \%$ with least $\left(\mathrm{IC}_{50} 0.0449 \mu \mathrm{g} / \mathrm{ml}\right.$ ), and the no toxicity against brine shrimp (LD 503423.156 ). Furthermore, no toxicity in all extracts was observed. The present study is the first evaluation regarding the characterization of E. aegyptiaca and its safety, and the results demonstrate its antioxidant potential and suggest its safe therapeutic use. The results suggest that methanol extract is a rich source of phytochemicals and exhibits highest amount of and total phenolic, flavonoid content and significant antioxidant activity and it has no cytotoxic activity. E. aegyptiaca plant can be regarded as a promising Source of naturally occurring potential antioxidants.
\end{abstract}

Keywords: Euphorbia aegyptiaca, Sudan, Antioxidant, Total phenolic, total flavonoid, Cytotoxicity.

Article Info: Received 04 Jan 2020; Review Completed 12 Feb 2020; Accepted 19 Feb 2020; Available online 15 March 2020

\section{Cite this article as:}

Osman Adam OA, Abadi RSM, Ayoub SMH, Antioxidant activity, Total Phenolic and Flavonoid Contents and Cytotoxic activity of Euphorbia aegyptiaca, Journal of Drug Delivery and Therapeutics. 2020;10(2):37-41

http://dx.doi.org/10.22270/jddt.v10i2.3911

*Address for Correspondence:

Osman Adam Osman Adam, Department of Pharmacognosy, Faculty of Pharmacy, Al-Neelain University. Khartoum, Sudan

\section{INTRODUCTION}

Researches in the field of plant antioxidant focus on antioxidant agents that can protect biological components from oxidative damage [1]. Dietary intake of phenolic compounds correlates with reduced coronary heart disease, cancer mortality and protective in many health-related properties, such as antioxidant, anticancer, antiviral and anti-inflammatory activities [2, 3, 4]. On the other hand, concern about the safety of the commonly used synthetic antioxidants such as butylated hydroxyanisole (BHA) and tertiary butylhydroquinone (TBHQ) has led to increased interest in plant antioxidants [5].

The genus Euphorbia aegyptiaca (Euphorbiaceae) is considered as a large family of flowering plants comprising around 300 genera with 7,500 species [6]. E. aegyptiaca known locally in Sudan as umm lebaina or malbaine. The whole plant is used against scorpion bites. In Sudanes traditional medicine as wellas for treatment of inflammatory conditions like rheumatoid arthritis, conjunctivitis and dermatitis [7]. Euphorbia species contain phytochemical constituents like flavonoids, coumarins, triterpenoids, lignans and alkaloids [8, 9].

To date, to the best of our knowledge there has been no report on the quantitative determination of total phenolic and flavonoid contents and cytotoxic activity of $E$. aegyptiaca. The aim of the present study was to screen the phytochemicals and to assess the antioxidant activity; total phenolic and flavonoid contents and cytotoxic activity of $E$. aegyptiaca. 


\section{MATERIAL AND METHODS}

\section{Sample collection}

Whole plant of was collected in the White Nile state, Sudan, during February 2016. The identity of the plant was confirmed at the Medicinal and Aromatic Plants Research Institute (MAPRI), Khartoum, Sudan and the voucher specimens were deposited in the herbarium. The plant was dried for 15 days under the shade, then pulverized by mechanical grinder and stored in air-tight containers till use.

\section{Chemicals}

The chemicals and reagents used were of analytical grade. nHexane, Chloroform, Methanol, Dimethyl sulfoxide (DMSO), Gallic acid, ascorbic acid, aluminum chloride, sodium acetate and sodium carbonate were purchased from SDFCL, India. Ethanol LR, was obtained from Duksan, South Korea. 2.2Di (4-tert-octylphenyl)-1-picryl-hydrazyl (DPPH) and Quercetin were purchased from Sigma-Aldrich, UK. FolineCiocalteu reagent was purchased from $\mathrm{CDH}$, India.

\section{Apparatus}

Grinder (Disk Mill Model, FFC-15, China), Sensitive Balance (Rad wag, As 220/c/2, Poland), Soxhlet apparatus, heat mantel, Rotary evaporator (Heidolph OB2000 Heidolph VV2000, Germany), Ultraviolet (UV/vis-240 (PC) S, Double beam) Spectrophotometer (Shimadzu Japan).

\section{Preparation of extracts}

Five hundred grams were extracted successively with 2L nhexane, chloroform and methanol successively in a Soxhlet apparatus. The extracts were filtered using Whatman filter paper no. 1, and the filtrates were concentrated to dryness using a rotary evaporator. The percentage yield of the extracts was determined based on dry weight (d.w). The samples were kept in the refrigerator at $5^{\circ} \mathrm{C}$ until further analysis.

\section{Phytochemical Screening of extracts:}

The prepared $n$-hexane, chloroform and methanol extracts were used for the tests according to methods described by Harbone [10], Sofowora [11], Martinez \& Valencia [12] with few modifications.

\section{Antioxidant activity:}

\section{DPPH radical scavenging assay:}

The DPPH radical scavenging assay was performed according to the method of Shimada et. al., (1992) [13], with some modification. In 96-wells plate, the test samples were allowed to react with 2, 2-Di (4-tert-octylphenyl)-1-picrylhydrazylstable free radical (DPPH) for half an hour at $37^{\circ} \mathrm{C}$. The concentration of DPPH was kept as $(300 \mu \mathrm{M})$. The test samples were dissolved in DMSO while DPPH was prepared in ethanol. After incubation, decrease in absorbance was measured at $\lambda$ : $517 \mathrm{~nm}$ using multiplate reader spectrophotometer. Percentage radical scavenging activity of samples was determined in comparison with a DMSO treated control group. All tests and analysis were run in triplicate.

\section{IC 50 Calculations:}

The $\mathrm{IC}_{50}$ test material, which possesses $50 \%$ inhibition of free radicals of all the extracts and their fractions, was determined by monitoring the effect of different concentrations ranging from $0.5-0.0035 \mathrm{mg} / \mathrm{ml}$. The $\mathrm{IC}_{50}$ of the extracts and their fractions were calculated using EZ-Fit Enzyme Kinetic Program (Perrella Scientific Inc, U. S.A).

\section{Determination of total phenolics content}

The Folin Ciocalteu reagent was used for analysis of total phenolic content in plant extracts was determined [14]. Briefly, Test sample of each extract was prepared in methanol and the concentration of $1 \mathrm{mg} / \mathrm{ml}$ was used in the analysis. $1 \mathrm{ml}$ of the extract was mixed with $1 \mathrm{ml}$ of FolinCiocalteu reagent. The solution was kept at $25^{\circ} \mathrm{C}$ for $5-8 \mathrm{~min}$ before adding $4 \mathrm{ml}$ of sodium carbonate solution $7.5 \%$ and adjusting the volume to $16 \mathrm{ml}$ with water. After $2 \mathrm{~h}$, the absorbance was measured at $765 \mathrm{~nm}$ against the blank. The samples were prepared in triplicate for each analysis and the mean value of absorbance was obtained. Gallic acid was used as standard for the calibration curve. The content of phenols in the extracts was expressed in terms of gallic acid equivalent (mg of GA/g of extract).

\section{Determination of total flavonoids content}

The total flavonoid content in the examined plant extracts was measured with an aluminium chloride colorimetric assay [15]. A test sample of each extract was prepared in methanol and the concentration of $1 \mathrm{mg} / \mathrm{ml}$ was used in the analysis. An aliquot $1 \mathrm{ml}$ of extract or a standard solution of Quercetin $(0.05,0.1,0.2,0.3,0.4$ and $0.5 \mathrm{mg} / \mathrm{ml})$ was added to a $10 \mathrm{ml}$ volumetric flask, containing $4 \mathrm{ml}$ of distilled water. To the flask was added $0.3 \mathrm{ml} 5 \% \mathrm{NaNO}_{2}$. After $5 \mathrm{~min}, 0.3 \mathrm{ml}$ $10 \% \mathrm{ALCl}_{3}$ was added. At the sixth minute, $2 \mathrm{ml} 1 \mathrm{M} \mathrm{NaOH}$ was added and $2.4 \mathrm{ml}$ was added $\mathrm{H}_{2} \mathrm{O}$. The solution was mixed well and the absorbance was measured against a prepared reagent blank at $510 \mathrm{~nm}$ with an UV- vis spectrophotometer. The data of the total flavonoids content of the extracts were expressed as milligrams of quercetin equivalents (QE) Per 100 grams dry mass (mg of Q/g of extract). All samples were analyzed in duplicates.

\section{Toxicity testing against the brine shrimp:}

\section{Storage of Artemia Salina eggs:}

Eggs of Artemia Salina were stored at low temperatures (4응 $\mathrm{C})$, to remain viable for many years.

\section{Hatching shrimp:}

Brine shrimp eggs, Artemia Salina were hatched in artificial seawater prepared by dissolving $38 \mathrm{~g}$ of sea salt in one liter of distilled water. After $24-72 \mathrm{~h}$ incubation at room temperature $\left(37^{\circ} \mathrm{C}\right)$, the larvae were attracted to one side of the vessel with a light source and then collected with a pipette. Larvae were separated from the eggs by aliquoting them three times in small beakers containing artificial seawater.

\section{Brine shrimp assay:}

Bioactivity of the extract was monitored by the brine shrimp lethality test [16]. Brine shrimp lethality bioassay was carried out to investigate the cytoxicity of extracts and $50 \mathrm{mg}$ of Artemia Salina (Leach) eggs was added to a hatching chamber containing artificial Sea water $(75 \mathrm{ml})$. The hatching chamber was kept under an inflorescent bulb for $48 \mathrm{~h}$ for the eggs to hatch into shrimp larvae. twenty mg of test extracts of the various plant species was separately dissolved in $2 \mathrm{ml}$ of methanol, then 500,50, and $5 \mu \mathrm{l}$ of each solution was transferred into vials corresponding to 1000,100 , and 10 $\mu \mathrm{g} / \mathrm{ml}$, respectively. Each dosage was tested in triplicate. Ten larvae of A. Salina Leach (taken $48-72 \mathrm{~h}$ after the initiation of hatching) were added to each vial (Figure 4). The final volume of solution in each vial was adjusted to $5 \mathrm{ml}$ with Sea water immediately after adding the shrimps. One drop of dimethyl sulphoxide (DMSO) was added to the test and control vials before adding the shrimps to enhance the solubility of test materials. $\mathrm{LD}_{50}$ values were determined at 
$95 \%$ confidence intervals by analyzing the data on a computer loaded with a "Finney Program." The concentration at which it could kill 50\% larvae (LD 50 ) was determined. $\mathrm{LD}_{50}$ values below 200ppm are generally considered as significant [17,18, and 19].

\section{Statistical analysis:}

Data were presented as means \pm S.D. Statistical analysis of assay results were performed using the Microsoft Excel program 2013 and Finney Program.

\section{RESULTS AND DISCUSSION}

\section{Percentage Yield of Extract}

The plant material was extracted successively by the Soxhlet extraction method using n-hexane, chloroform and methanol. The results showed the highest yield of methanol $(9.461 \%)$, followed by chloroform $(1.902 \%)$ and then $n-$ Hexane $(1.433 \%)$ as seen in Figure 1.

\section{Chemical Constituents:}

The phytochemical screening of three successive extracts prepared with n-hexane, Chloroform and Methanol, of $E$. aegyptiaca plant revealed the presence of various secondary metabolites: tannins, flavonoids, coumarins, saponins, sterols, terpenes and alkaloids. Anthraquinones and Cyanogenic glycoside were not detected. Phytochemical constituents of the E. aegyptiaca plant have been depicted in Table 1.

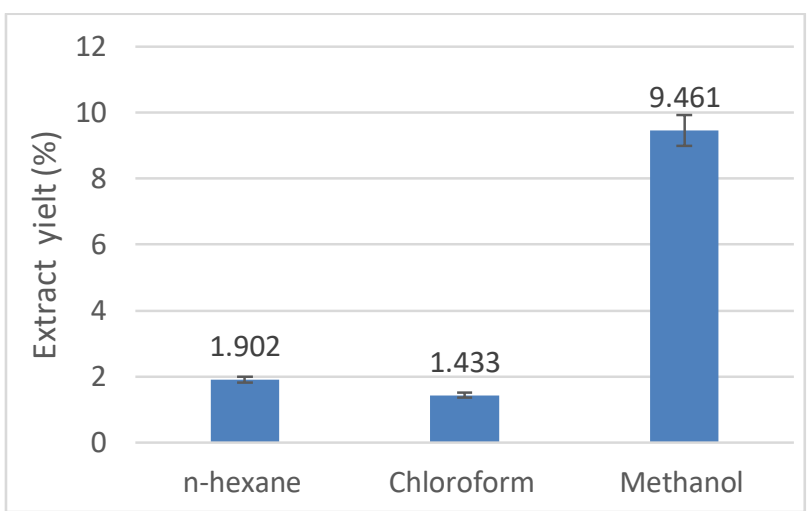

Figure 1: Percentage yield of different extracts of $E$. aegyptiaca plant.

Table 1: Preliminary phytochemical screening of E. aegyptiaca.

\begin{tabular}{|c|c|c|c|c|c|}
\hline \multirow[t]{2}{*}{ No. } & \multirow[t]{2}{*}{ Plant Constituents } & \multirow[t]{2}{*}{ Tests/reagents used } & \multicolumn{3}{|c|}{ Name of Extracts } \\
\hline & & & n-Hexane & Chloroform & Methanol \\
\hline 1 & Tannins & Ferric chloride test & + & - & +++ \\
\hline \multirow{3}{*}{2} & \multirow{3}{*}{ Flavonoids } & $\mathrm{ALCL}_{3} 1 \%$ test & + & - & ++ \\
\hline & & $\mathrm{KOH} 1 \%$ test & + & + & ++ \\
\hline & & Shinoda's test & + & + & +++ \\
\hline 3 & Coumarins & $\mathrm{NH}_{3} 10 \%$ & + & ++ & ++ \\
\hline 4 & Saponins & Froth Test & - & - & + \\
\hline 5 & Sterols & Salkowski's Test & + & ++ & ++ \\
\hline 6 & Terpenes & Liebermann Test & - & - & + \\
\hline 7 & Anthraquinones & Borntrager's test. & - & - & - \\
\hline 8 & Alkaloids & Mayer's reagent & + & + & + \\
\hline 9 & Cyanogenic glycosides & Guignard test & - & - & - \\
\hline
\end{tabular}

Key: + =Trace, ++ =Moderate, +++ =High, - =Negative.

\section{Total phenolic and total flavonoid contents}

The methanol extract showed the highest level of total phenolic contents $(173.49 \pm 2.427 \mathrm{mg}$ of $\mathrm{GAE} / \mathrm{g})$ and flavonoid content $(239.53 \pm 7.90 \mathrm{mg} \mathrm{QE} / \mathrm{g})$, Table 2. Plants with high phenolics and flavonoids contents possess remarkable antioxidant activity due to their redox properties and chemical structures.

Table 2: Total phenolic and flavonoid content of three extracts of E. aegyptiaca

\begin{tabular}{|c|l|l|l|}
\hline NO. & \multicolumn{1}{|c|}{ Extract } & $\begin{array}{c}\text { Total Phenolic content (mg of } \\
\text { GAE/g of extract) }\end{array}$ & $\begin{array}{c}\text { Total Flavonoid content (mg } \\
\text { of QE/g of extract) }\end{array}$ \\
\hline 1 & n-Hexane & $15.823 \pm 0.348$ & $55.072 \pm 4.56$ \\
\hline 2 & Chloroform & $18.50 \pm 0.0483$ & $26.087 \pm 13.69$ \\
\hline 3 & Methanol & $173.49 \pm 2.427$ & $239.53 \pm 7.90$ \\
\hline
\end{tabular}

Key: GAE= Gallic acid equivalent, $\mathrm{QE}=$ Quercetin equivalent, Values are expressed as means of triplicate determinations $\pm \mathrm{SD}$. 


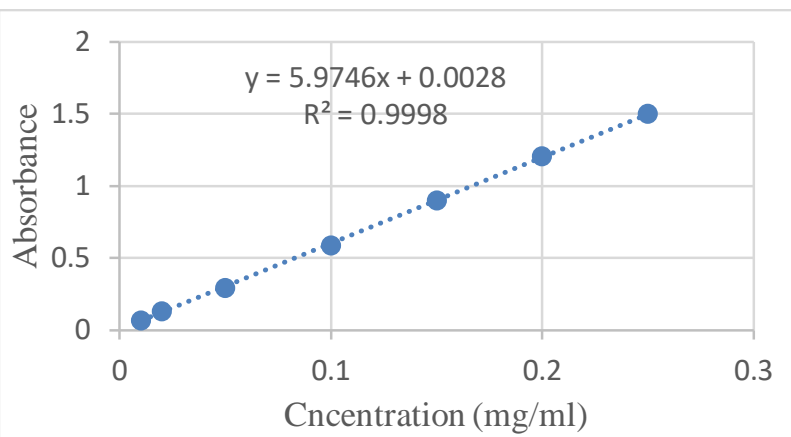

Figure 2: Calibration curve for Gallic acid.

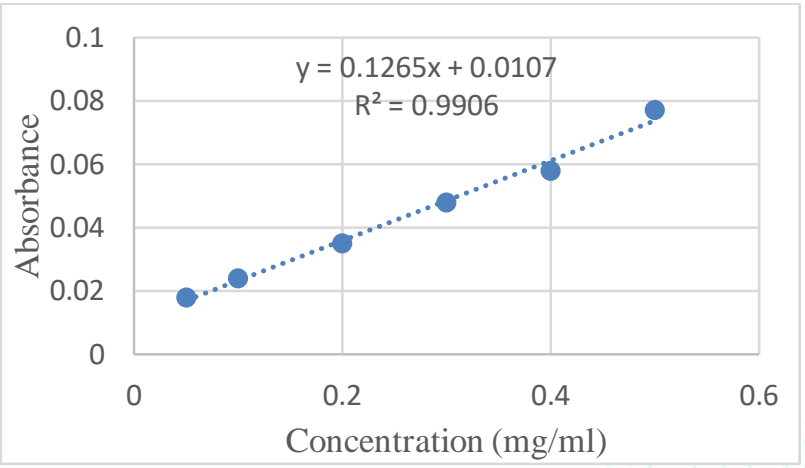

Figure 3: Calibration curve for Quercetin.

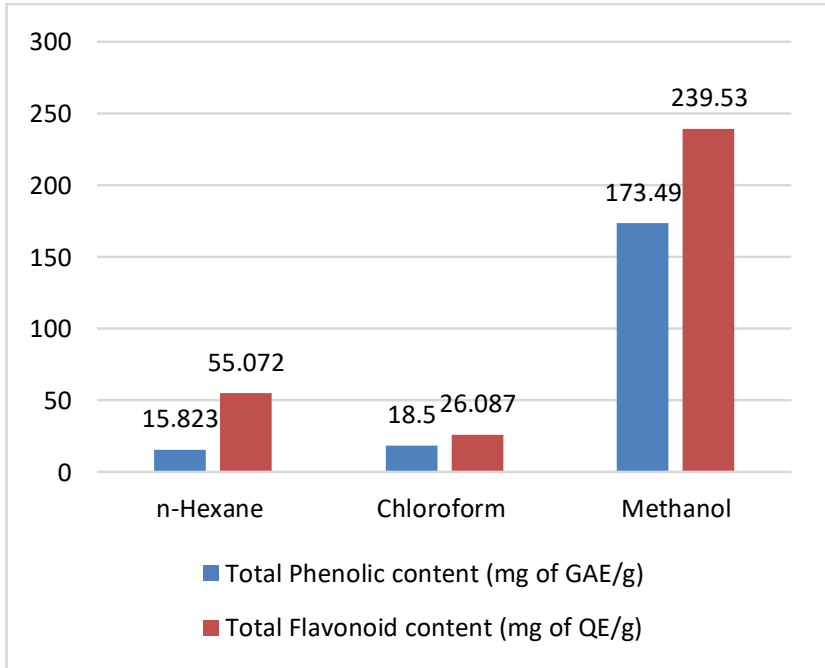

Figure 4: Comparison of Total Phenolic content and Total Flavonoid content of Euphorbia aegyptiaca.

\section{Antioxidant activity}

The free radical scavenging activity of E. aegyptiaca extracts were n-hexane $(07 \%)$, chloroform $(23 \%)$ but methanol showed the highest activity $(89 \%)$ with least $\mathrm{IC}_{50} 0.0449$ $\mu \mathrm{g} / \mathrm{ml}$, The results were reported Table 3 .

Table 3: The DPPH radical scavenging activity and $\mathrm{IC}_{50}$ Value of three extracts of $E$. aegyptiaca.

\begin{tabular}{|c|l|c|c|}
\hline NO. & \multicolumn{1}{|c|}{ Extract } & $\begin{array}{c}\text { \%RSA } \pm \text { SD } \\
\text { (DPPH) }\end{array}$ & $\begin{array}{c}\mathbf{I C}_{\mathbf{5 0}} \pm \mathbf{S D} \boldsymbol{\mu g} / \mathbf{m l} \\
\text { (DPPH) }\end{array}$ \\
\hline 1 & n-Hexane & $07 \pm 0.03$ & - \\
\hline 2 & Chloroform & $23 \pm 0.05$ & - \\
\hline 3 & Methanol & $89 \pm 0.02$ & $0.0449 \pm 0.01$ \\
\hline & Control (PG) & $91 \pm 0.01$ & $0.077 \mu \mathrm{g} / \mathrm{ml} \pm 0.01$ \\
\hline
\end{tabular}

The results are presented as mean \pm SEM. Each experiment was repeated three times; $(n=3)$

Key: $\mathrm{RSA}=$ Radicals scavenging activity, $\mathrm{DPPH}=1,1$-diphenyl-2-picryl hydrazyl. $\mathrm{IC}_{50}=$ half concentration of inhibition. The lower $\mathrm{IC}_{50}$ value indicates the greater overall effectiveness of the antioxidant. Control (PG) = Propyl Gallate.

\section{Cytotoxic activity:}

Cytotoxicity study of E. aegyptiaca extracts was conducted by brine shrimp lethality test. The results (Table 4 ), showed that $\mathrm{LD}_{50}$ Values above $1000 \mu \mathrm{g} / \mathrm{ml}$ were regarded as nontoxic [20].

Table 4. Cytotoxicity of E. aegyptiaca extract on (brine shrimp) by Finney probity analysis (model).

\begin{tabular}{|c|l|l|c|}
\hline No. & \multicolumn{1}{|c|}{ Extract } & \multicolumn{1}{|c|}{ LD50 } & Result \\
\hline 1 & n-Hexane & 37095928695.2 & No-Toxic \\
\hline 2 & Chloroform & 12204.187 & No-Toxic \\
\hline 3 & Methanol & 3423.156 & No-Toxic \\
\hline
\end{tabular}

Key: >1000: non-toxic. $\mathrm{LD}_{50}=$ Lethal Concentration calculated by Probit analysis, D. Jon Finny.

\section{CONCLUSION}

It is proved that the methanol extract of E. aegyptiaca has the highest antioxidant activity, total phenolic and flavonoid contents. Furthermore, have no toxic effect. Therefore, it can be stated that E. aegyptiaca plant can be regarded as a promising candidate of natural antioxidant compounds with high values. These results might be helpful for treating diseases related to oxidative processes. The results of our investigations is a good starting points for Fractionation, isolation, purification and monitoring of activities of constituent according to their antioxidant effect. Identification and characterization of the chemical structure of these phenolics and flavonoids of the methanolic extract of E. aegyptiaca, Could be a remarkable addition to the global database.

\section{REFERENCES}

1. Zhang HY, Yang DP, Tang GY. Multipotent antioxidants: from screening to design. Drug Discovery Today; 2006; 11(1516):749-54.

2. Halliwell, B. Dietary polyphenols: Good, bad, or indifferent for your health? Cardiovascular Research, 2007; 73:341-347.

3. Kubola, J., \& Siriamornpun, S. Phenolic contents and antioxidant activities of bitter gourd (Momordica charantia L.) leaf, stem and fruit fraction extracts in vitro. Food Chemistry, 2008; 110:881-890. 
4. Mohsen, S. M., \& Ammar, A. S. M. Total phenolic contents and antioxidant activity of corn tassel extracts. Food Chemistry, 2009; 112:595-598.

5. F. Heshmati-Afshar, A. Delazar, H. Nazemiyeh, S. Esnaashari, and S. B. Moghadam, "Comparison of the total phenol, flavonoid contents and antioxidant activity of methanolic extracts of Artemisia spicigera and A. splendens growing in Iran," Pharmaceutical Sciences, 2012; 18(3):165-170.

6. Rahman AH MM and Akter M. Taxonomy and Medicinal Uses of Euphorbiaceae (Spurge) Family of Rajshahi, Bangladesh. Res. Plant Sci, 2013; 1(3):74-80.

7. Marium A. Abo-dola, Mohamed F. Lutfi. Anti-inflammatory activity of Euphorbia aegyptiaca extract in rats. International Journal of Health Sciences. Qassim University; 2016; 10.1.

8. Liu ZG, Li ZL, Bai J, Meng DL, Li N, Pei YH, Zhao F, Hua HM. Anti-inflammatory diterpenoids from the roots of Euphorbia ebracteolata. J Nat Prod, 2014; 77(4):792-9.

9. Llanes-Coronel DS, Gámez-Díaz LY, Suarez-Quintero LP, Páez LJ, Torres F, Echeverri F, Ponte-Sucre A, Patiño PJ, TrujilloVargas CM. New promising Euphorbiaceae extracts with activity in human lymphocytes from primary cell cultures. Immunopharmacol Immunotoxicol, 2011; 33(2):279-90.

10. Harbone JB. Phytochemical methods: a guide to modern techniques of plant analysis. Champon and Hall Ltd, 1984, 49188.

11. Sofowora A. Medicinal Plants and Traditional Medicines in Africa. Chichester John, Willey \& Sons New York, 1993, 256.

12. Martinez A, Valencia G, Marcha fitoquimica. In Manual de Prácticas de Farmacognosiay Fitoquímica: 1999. 1. st edition.
Medellin: Universidadde Antioquia; Phytochemical screening methods, 2003, 59-65.

13. Shimada K, Fujikawa K, Yahara K, Nakamura T. Antioxidant properties of xanthan on the abutoxidation of soybean oil in cyclodextrin emulsion. Journal of Agricultural Food Chemistry. 1992; 40:945-948.

14. Chun OK, Kim DO, Lee CY. Superoxide radical scavenging activity of the major polyphenols in fresh plums. J Agric Food Chem 2003; 51:8067-72.

15. D. Marinova, F. Ribarova, M. Atanassova, J. Univ, Chem. Tech. Met. (Sofia), 2005; 40(3):255-260.

16. Mayer, B.N., Ferrigni, N.R., Putnam, J.E., Jacobsen, L.B., Nichols, D.E. and McLaughlin, J.L. Brine shrimp: a convenient bioassay for active plant constituents. Planta Medica, 1982; 45:31-34.

17. Kupahan, S.M., P.S. Steyn, M.D. Grove, S.M. Horsefield and S.W. Meitner. Tumor inhibitors, xxxv Myrsine saponin. The active principle of Myrsine africana. J. Med. Chem., 1969; 12:167169.

18. Ma, W.W., J.E. Anderson, C.J. Chang, D.L. Smith and J.L. McLaughlin. Majorenolide and majorynolide. A new pair of cytotoxic and pesticidal alkene-alkyne $\delta$-lactones from Persia major. J. Nat. Pdts, 1989; 52:1265-1266.

19. Oladimeji, H.O, Nia, R and Essien, E. E. In-vitro Anti-Microbial and Brine-Shrimp Lethality Potential of the Leaves and Stem of Calotropis procera (Ait). African Journal of Biomedical Research, 2006; 9:205 - 211.

20. McLaughlin JL, Rogers LL, Anderson JE. The use of biological assay to evaluate botanicals. Drug Inf J, 1998; 32:513-524. 